\title{
Superficial CD34-positive fibroblastic tumor: report of 18 cases of a distinctive low-grade mesenchymal neoplasm of intermediate (borderline) malignancy
}

\author{
Jodi M Carter ${ }^{1}$, Sharon W Weiss ${ }^{2}$, Konstantinos Linos ${ }^{2}$, David J DiCaudo ${ }^{3}$ and \\ Andrew L Folpe ${ }^{1}$ \\ ${ }^{1}$ Department of Laboratory Medicine and Pathology, Mayo Clinic, Rochester, MN, USA; ${ }^{2}$ Department of \\ Pathology and Laboratory Medicine, Emory University, Atlanta, GA, USA and ${ }^{3}$ Department of \\ Dermatology, Mayo Clinic, Scottsdale, AZ, USA
}

\begin{abstract}
Fibroblastic mesenchymal tumors show a spectrum of biological behavior, from benign to fully malignant. We report our experience of two decades with a distinctive, previously undescribed low-grade fibroblastic tumor of the superficial soft tissues. Eighteen cases were identified within our consultation files, previously coded as 'low-grade sarcoma, not further classified' and 'malignant fibrous histiocytoma, low grade'. The tumors occurred in adults (median age 38 years, range 20-76 years) of either sex (10 males and 8 females), ranged in size from 1.5 to $10 \mathrm{~cm}$ (mean $4.1 \mathrm{~cm}$ ), and were confined to the superficial soft tissues of the thigh $(N=5)$, knee $(N=2)$, and other sites. Histological features included a fascicular growth pattern of the neoplastic spindled cells with striking, often bizarre cellular pleomorphism and variably prominent nucleoli. Necrosis was seen in one case. All cases showed strong, diffuse CD34 positivity and $68 \%$ of tested cases demonstrated focal cytokeratin expression. Desmin, ERG, FLI-1, smooth muscle actin, and S100 protein were negative. TP53 overexpression was absent. Fluorescence in-situ hybridization studies for TGFBR3 and/or MGEA5 rearrangements were negative in all tested cases. Clinical followup was available in 13 patients (median duration of 24 months; range 1-104 months). Twelve of 13 patients had no disease recurrence. One patient had regional lymph node metastases, 7 years after incomplete excision of the primary tumor. All patients are currently alive and disease free. The unique clinicopathological features of superficial CD34-positive fibroblastic tumor define them as a novel subset of low-grade fibroblastic neoplasms, best considered to be of borderline malignancy.
\end{abstract}

Modern Pathology (2014) 27, 294-302; doi:10.1038/modpathol.2013.139; published online 26 July 2013

Keywords: CD34; immunohistochemistry; mesenchymal tumors; skin tumors

Most fibroblastic tumors of deep soft tissue fall into well-defined clinicopathological categories, such as desmoplastic fibroblastoma (collagenous fibroma), ${ }^{1}$ adult fibrosarcoma, ${ }^{2}$ low-grade fibromyxoid sarcoma, ${ }^{3}$ and sclerosing epithelioid fibrosarcoma. ${ }^{4}$ Although these tumors may also rarely occur in superficial (suprafascial) locations, superficially located fibroblastic tumors more often represent different entities, such as myxofibrosarcoma (myxoid malignant fibrous histiocytoma), ${ }^{5,6}$ fibrosarcoma

Correspondence: Dr AL Folpe, MD, Department of Laboratory Medicine and Pathology, Mayo Clinic, 200 1st Street SW, Rochester, MN 55905, USA.

E-mail: Folpe.Andrew@Mayo.edu

Received 10 May 2013; revised 11 June 2013; accepted 12 June 2013; published online 26 July 2013 arising in dermatofibrosarcoma protuberans, ${ }^{7}$ myxoinflammatory fibroblastic sarcoma (inflammatory myxohyaline tumor of distal extremities),,${ }^{8,9}$ and pleomorphic hyalinizing angiectatic tumor. ${ }^{10,11}$

Over the past two decades we have seen in consultation a number of cases of a distinctive fibroblastic tumor of the superficial soft tissues, characterized in part by striking pleomorphism, very low mitotic activity, and CD34 immunoreactivity, and not clearly corresponding to a previously described entity. The present study was undertaken in order to more fully characterize the clinicopathological features of these rare lesions, which we have termed 'superficial CD34-positive fibroblastic tumor', and to evaluate their relationship, if any, to other superficial fibroblastic sarcomas, in particular undifferentiated pleomorphic sarcoma ('malignant 
fibrous histiocytoma'), myxofibrosarcoma ('myxoid malignant fibrous histiocytoma'), hemosiderotic fibrolipomatous tumor/'early' pleomorphic hyalinizing angiectatic tumor, classical pleomorphic hyalinizing angiectatic tumor, and myxoinflammatory fibroblastic sarcoma.

\section{Materials and methods}

The study was approved by the Mayo Clinic and Emory University Institutional Review Boards. The consultation archives of two of the authors (ALF and SWW) were searched for cases previously coded as 'low-grade sarcoma, not further classified' and 'malignant fibrous histiocytoma, low grade', yielding 18 cases. One case had previously been reviewed by another group of expert soft-tissue pathologists, and was considered to most likely represent an unusual variant of pleomorphic hyalinizing angiectatic tumor, lacking characteristic vascular changes. All available slides from these 18 cases were re-reviewed by three of the authors (JMC, SWW, and ALF). Clinical follow-up information was obtained from existing medical records and from the referring clinicians and pathologists.

Immunohistochemistry was performed on deparaffinized, rehydrated sections obtained from formalin-fixed, paraffin-embedded tissue, using antibody-specific epitope retrieval techniques with the Dako Envision (Dako, Carpinteria, CA, USA) automated system for detection of the following primary antigens: CD34 (QBEnd/10, 1:50, Leica Biosystems, Buffalo Grove, IL, USA), cytokeratins
(OSCAR, >1:40, Covance, Princeton, NJ, USA), desmin (DE-R-11, 1:50-1:100, Leica) ERG (9FY, 1:50-1:100, Biocare Medical, Concord, CA, USA), FLI-1 (1:25-1:100, Cell Marque, Rocklin, CA, USA), Ki-67 (MIB-1, 1:75-1:150, Dako), TP53 (DO-7, prediluted, Ventana), SMARCB1 (BAF47/INI1; 25, BD Transduction Laboratories, Franklin Lakes, NJ, USA), smooth muscle actin (1A4, 1:50-1:100, Dako), and S100 protein (polyclonal, 1:400, Dako). Five cases were analyzed for rearrangements of TGFBR3 and MGEA5 in the laboratory of Dr Cristina Antonescu (Memorial Sloan Kettering Cancer Center, New York, NY, USA) by fluorescence in-situ hybridization (FISH) using previously described methods. ${ }^{12}$

\section{Results}

The clinicopathological features of the 18 cases of superficial CD34-positive fibroblastic tumor are summarized in Table 1 . The lesions occurred exclusively in adults (median age 38 years, range 20-76 years) of either sex (10 males and 8 females) and typically presented as painless, slow-growing masses present for at least 1 year, ranging in size from 1.5 to $10 \mathrm{~cm}$ (mean $4.1 \mathrm{~cm}$ ). The majority of cases $(67 \%)$ occurred in the lower limb, including the thigh (six cases, 30\%), the soft tissues around the knee (two cases, 11\%), and the buttock, lower leg and foot (one case each). Other involved sites included the arm (two cases), groin (two cases), neck, shoulder, hip, and vulva (one case each). All tumors were confined to the superficial fibroadipose tissues, with minimal or absent involvement of the

Table 1 Clinicopathological features

\begin{tabular}{|c|c|c|c|c|c|c|c|}
\hline $\begin{array}{l}\text { Case } \\
\text { No. }\end{array}$ & $\begin{array}{c}\text { Age } \\
\text { (year)/ } \\
\text { sex }\end{array}$ & $\begin{array}{l}\text { Site/size } \\
(\mathrm{cm})\end{array}$ & $\begin{array}{l}\text { Preoperative } \\
\text { duration }\end{array}$ & Depth & Treatment/margin status & $\begin{array}{l}\text { Local } \\
\text { recurrences }\end{array}$ & $\begin{array}{c}\text { Outcome/follow-up } \\
\text { duration (months) }\end{array}$ \\
\hline 1 & $20 / \mathrm{M}$ & Thigh/3.1 & Unknown & Suprafascial & $\begin{array}{l}\text { Local excision, then interval regional } \\
\text { lymphadenectomy/marginal }\end{array}$ & $\begin{array}{l}\text { No, regional LN } \\
\text { metastasis }\end{array}$ & ANED/104 \\
\hline 2 & $21 / \mathrm{F}$ & $\mathrm{Leg} / 2$ & Unknown & Suprafascial & Local excision/marginal & No & ANED/30 \\
\hline 3 & $25 / \mathrm{M}$ & Groin/7.5 & $\begin{array}{l}\text { Unknown (rapid } \\
\text { enlargement) }\end{array}$ & Suprafascial & Local excision/marginal & No & $\mathrm{ANED} / 1$ \\
\hline 4 & $25 / \mathrm{M}$ & Foot/3.8 & 4 years & Suprafascial & Wide excision/wide & No & ANED/17 \\
\hline 5 & $26 / \mathrm{M}$ & Thigh/6.5 & Unknown & Suprafascial & Local excision, then wide excision/wide & No & $\mathrm{ANED} / 7$ \\
\hline 6 & $26 / \mathrm{M}$ & Thigh/2.2 & 'Several years' & Suprafascial & Local excision/marginal & NA & NA \\
\hline 7 & $28 / \mathrm{M}$ & Thigh/1.5 & Unknown & Suprafascial & Local excision/Marginal & No & ANED/24 \\
\hline 8 & $32 / \mathrm{M}$ & $\begin{array}{l}\text { Shoulder/ } \\
\text { unknown }\end{array}$ & 14 years & Suprafascial & Local excision/marginal & No & $\mathrm{ANED} / 2$ \\
\hline 9 & $37 / \mathrm{F}$ & Vulva/10 & Unknown & Suprafascial & Local excision/marginal & NA & NA \\
\hline 10 & $38 / \mathrm{F}$ & Neck/1.5 & 6 years & Suprafascial & Local excision/Marginal & No & ANED/38 \\
\hline 11 & $44 / \mathrm{F}$ & $\begin{array}{l}\text { Popliteal } \\
\text { fossa/6.5 }\end{array}$ & At least 1 year & Suprafascial & $\begin{array}{l}\text { Local excision, then wide excisions }{ }^{2} \text { and } \\
\text { RT/wide }\end{array}$ & No & ANED/20 \\
\hline 12 & $45 / \mathrm{M}$ & $\begin{array}{l}\text { Knee/ } \\
\text { unknown }\end{array}$ & Unknown & Suprafascial & Local excision/marginal & NA & NA \\
\hline 13 & $46 / \mathrm{M}$ & $\mathrm{Hip} / 2$ & Unknown & Suprafascial & Local excision/marginal & NA & NA \\
\hline 14 & $48 / \mathrm{M}$ & $\mathrm{Arm} / 2.7$ & Unknown & Suprafascial & $\begin{array}{l}\text { Local excision, preoperative RT, then } \\
\text { wide excision/Wide }\end{array}$ & No & $\mathrm{ANED} / 4$ \\
\hline 15 & $51 / \mathrm{F}$ & $\begin{array}{l}\text { Arm/ } \\
\text { unknown }\end{array}$ & Unknown & Suprafascial & Local excision/marginal & NA & NA \\
\hline 16 & $53 / \mathrm{F}$ & Groin/3.4 & 20 years & Suprafascial & Local excision, then wide excision/wide & No & ANED/53 \\
\hline 17 & $57 / \mathrm{F}$ & Thigh/7.4 & Unknown & Suprafascial & Local excision, then wide excision/wide & No & $\mathrm{ANED} / 3$ \\
\hline 18 & $76 / \mathrm{F}$ & Buttock/2 & 'Many years' & Suprafascial & Local excision/marginal & No & $\mathrm{ANED} / 3$ \\
\hline
\end{tabular}

Abbreviations: ANED, alive no evidence of disease; F, female; LN, lymph node; M, male; NA, not available; RT, radiotherapy. 

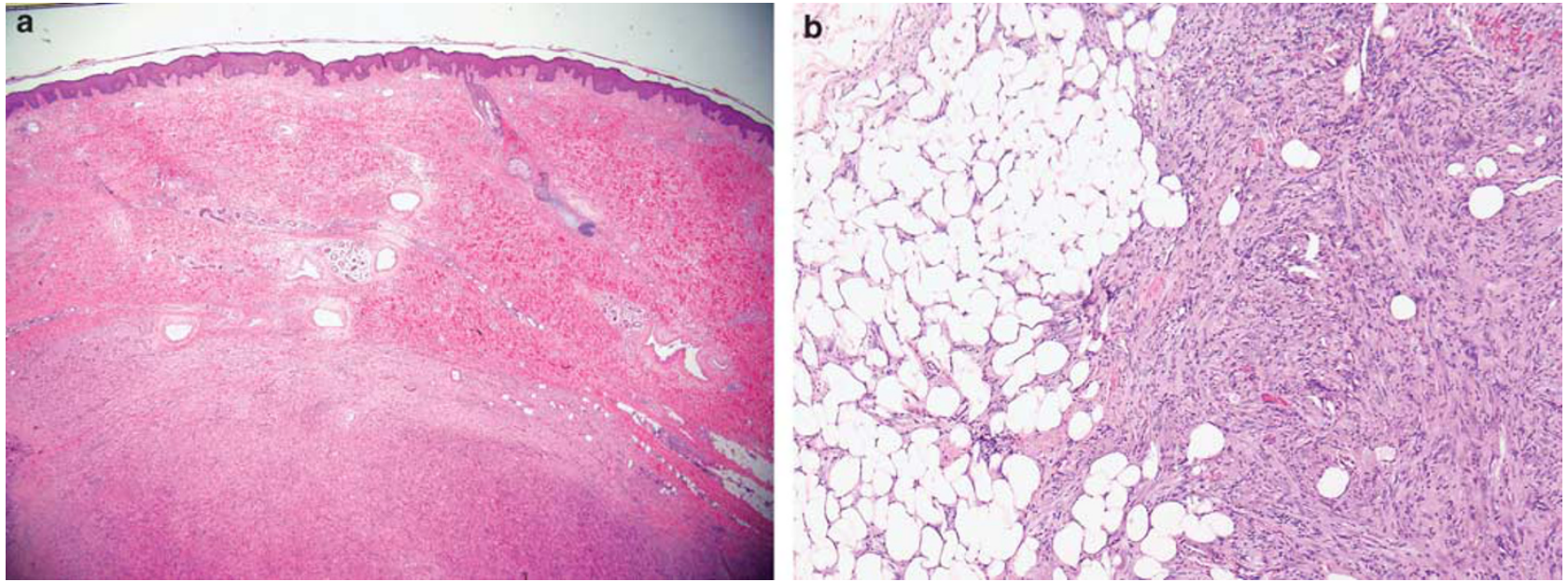

Figure 1 All tumors arose in suprafascial locations, as in this example showing involvement of the deep dermis and subcutaneous fat (a). Although the lesions had a relatively well-circumscribed appearance at low-power magnification (a), infiltrative growth into the surrounding fibroadipose tissue was invariably present, at least focally (b).

subjacent muscle. No patient had a history of a prior cutaneous neoplasm in the same location.

Grossly, the tumors were described as firm, yellow to tan, and variably gelatinous in appearance. Microscopically, they grew in a generally circumscribed but infiltrative fashion (Figures 1a and b), and were composed of moderately to sometimes highly cellular fascicles and sheets (Figures 2a-c) of spindled-to-epithelioid cells with an abundant granular, fibrillary, or glassy cytoplasm (Figures $3 \mathrm{a}-\mathrm{c})$. An arborizing capillary-sized vasculature was frequently present, particularly in areas showing a fascicular growth pattern. A sub-population of tumor cells showed xanthomatous change. Most cells displayed marked nuclear pleomorphism, with bizarre, lobated, hyperchromatic nuclei containing one or more large nucleoli, reminiscent of those seen in myxoinflammatory fibroblastic sarcoma (Figures 4a-c). Intranuclear cytoplasmic pseudoinclusions and a mixed chronic inflammatory cell infiltrate including numerous mast cells, as are seen in pleomorphic hyalinizing angiectatic tumor, were frequently present. However, other morphological features of pleomorphic hyalinizing angiectatic tumor and/or myxoinflammatory fibroblastic sarcoma such as ectatic, hyalinized blood vessels, myxoid zones with pseudolipoblasts, hyalinized areas with a 'burned out' appearance, and intracytoplasmic hemosiderin pigment were not present. Similarly, areas resembling conventional dermatofibrosarcoma protuberans or fibrous histiocytoma were entirely absent. Despite the moderate to occasionally high cellularity and marked nuclear atypia, mitotic figures were extremely uncommon, usually numbering $<1 / 50$ high-powered fields (HPFs; Figures 5a and b). Atypical mitotic figures were absent and necrosis was present in only one case. Mitotic activity of $>1 / 50 \mathrm{HPF}$ was seen in the re-excision specimen of one case.
By immunohistochemistry, all tumors showed strong, diffuse CD34 positivity (Figure 6a). Limited cytokeratin expression was seen in the neoplastic cells of 11 out of 16 tested cases (69\%; Figure 6b). All tested cases lacked expression of FLI-1 and ERG proteins and showed retained expression of the SMARCB1 tumor suppressor gene product (Figure 6c). S100 protein, desmin, and smooth muscle actin were negative in all tested cases. The Ki-67-labeling index was extremely low in all tested cases $(<1 \%$ of cells). All tested cases lacked TP53 overexpression (Figure 6d). The five cases tested by FISH for TGFBR3 and/or MGEA5 rearrangements were negative (Figure 7).

Clinical follow-up was available for 13 of 18 $(72 \%)$ patients, with a median duration of 24 months (range 1-104 months). Of these 13 patients, 12 are currently alive and are without evidence of disease. One patient with a superficial CD34positive fibroblastic tumor of the thigh suffered metastasis to an external iliac lymph node, 7 years after marginal excision of his primary tumor (Figure 8). The morphological and immunohistochemical features of this metastasis were identical to those of the primary tumor. Imaging studies did not show any evidence of distant metastatic disease, and no additional positive lymph nodes were identified in a complete pelvic lymphadenectomy; this patient is presently disease free.

\section{Discussion}

Superficial CD34-positive fibroblastic tumor is, in our experience, a unique lesion, not corresponding to any previously described soft tissue neoplasm. We suspect that many cases have been historically diagnosed as representing undifferentiated pleomorphic sarcomas or myxofibrosarcomas, based 

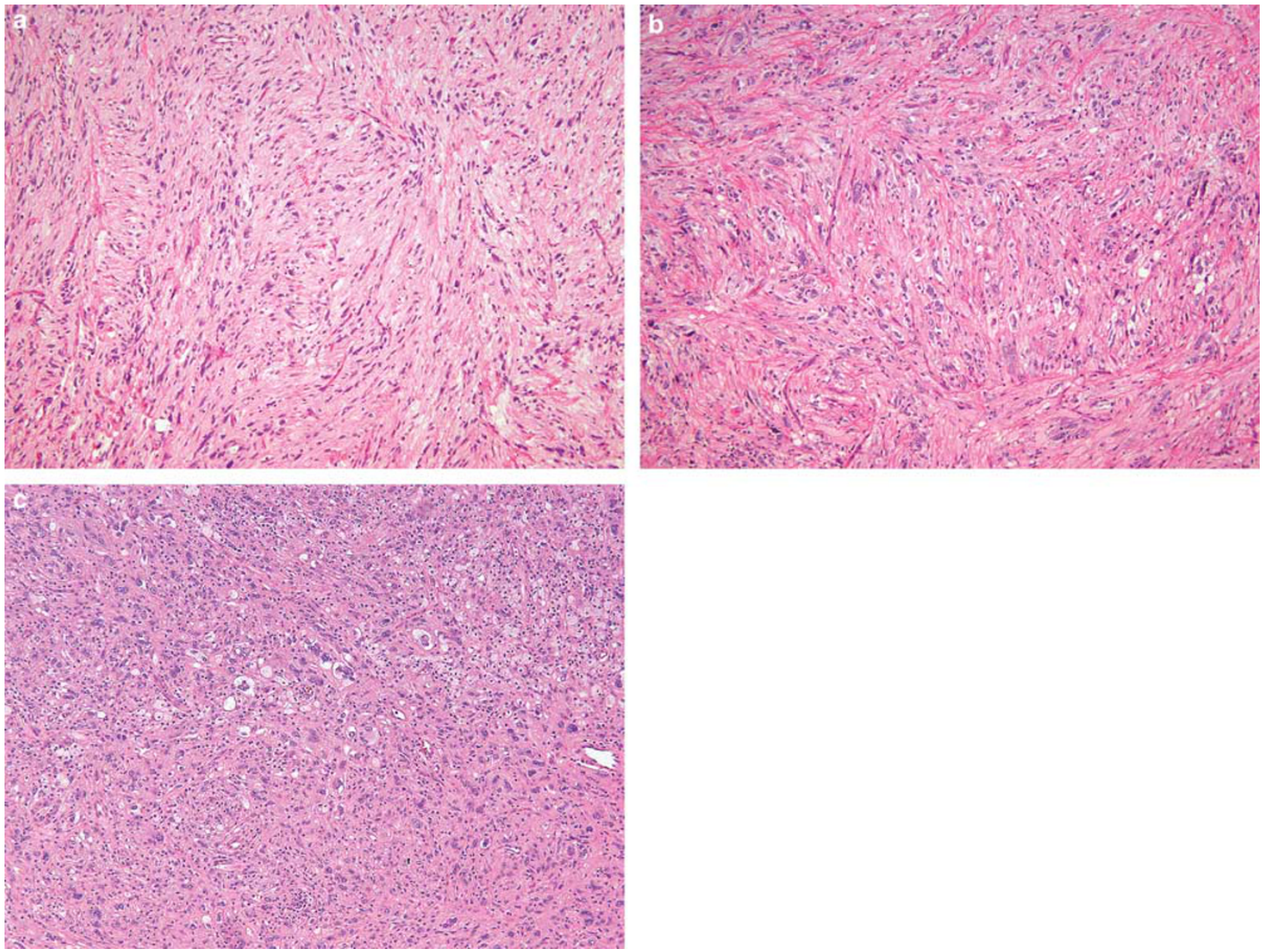

Figure 2 Most tumors consisted, at least in part, of relatively monomorphic spindled cells growing in intersecting fascicles, in association with an arborizing capillary vasculature (a). These relatively monomorphic areas gave way to larger areas showing greater pleomorphism and less well-formed fascicles (b) and to sheets of pleomorphic, epithelioid cells (c). Lipidized tumor cells were also commonly present.

chiefly on their very striking nuclear pleomorphism. Indeed, one of us (SWW) initially classified these tumors as 'low-grade malignant fibrous histiocytomas' before recognizing their unique clinical, morphological, and immunohistochemical features.

A number of features strongly suggest us that the lesions reported herein do not represent simply morphological variants of undifferentiated pleomorphic sarcoma, myxofibrosarcoma, or atypical fibroxanthoma. These tumors differ from undifferentiated pleomorphic sarcomas by virtue of their strikingly low mitotic rate and Ki-67-labeling index, their distinctive abundant granular to 'glassy'appearing cytoplasm, and their robust expression of CD34, a marker not generally expressed in quite so uniform a pattern in the great majority of undifferentiated pleomorphic sarcomas. Superficial CD34-positive fibroblastic tumors also appear to occur exclusively in a suprafascial location, in contrast to the great majority of undifferentiated pleomorphic sarcomas. Although myxofibrosarcomas typically arise in the superficial soft tissues of the extremities of older adults, they are characterized by the presence of myxoid nodules displaying an arborizing, thick-walled vasculature, and they lack the distinctive cytoplasmic and nuclear features of the present lesions (eg, intranuclear inclusions), and show a much higher mitotic rate and $\mathrm{Ki}$ 67-labeling index. ${ }^{5,6,13-15}$ Expression of CD34 may be seen occasionally in myxofibrosarcomas, ${ }^{16}$ although not typically to this degree, in our experience; co-expression of CD34 and cytokeratins is not a feature of myxofibrosarcoma. Although granular cell variants of atypical fibroxanthoma have been reported, atypical fibroxanthomas generally lack CD34 expression, show brisk mitotic activity, and arise in the dermis of sun-exposed skin. ${ }^{17-20}$ Finally, we did not detect TP53 overexpression in any studied case; TP53 overexpression is commonly present in high-grade pleomorphic sarcomas, myxofibrosarcomas, and atypical fibroxanthomas. ${ }^{21-26}$

The superficial location, striking pleomorphism, low mitotic rate, and chronic inflammatory cell infiltrate of superficial CD34-positive fibroblastic 

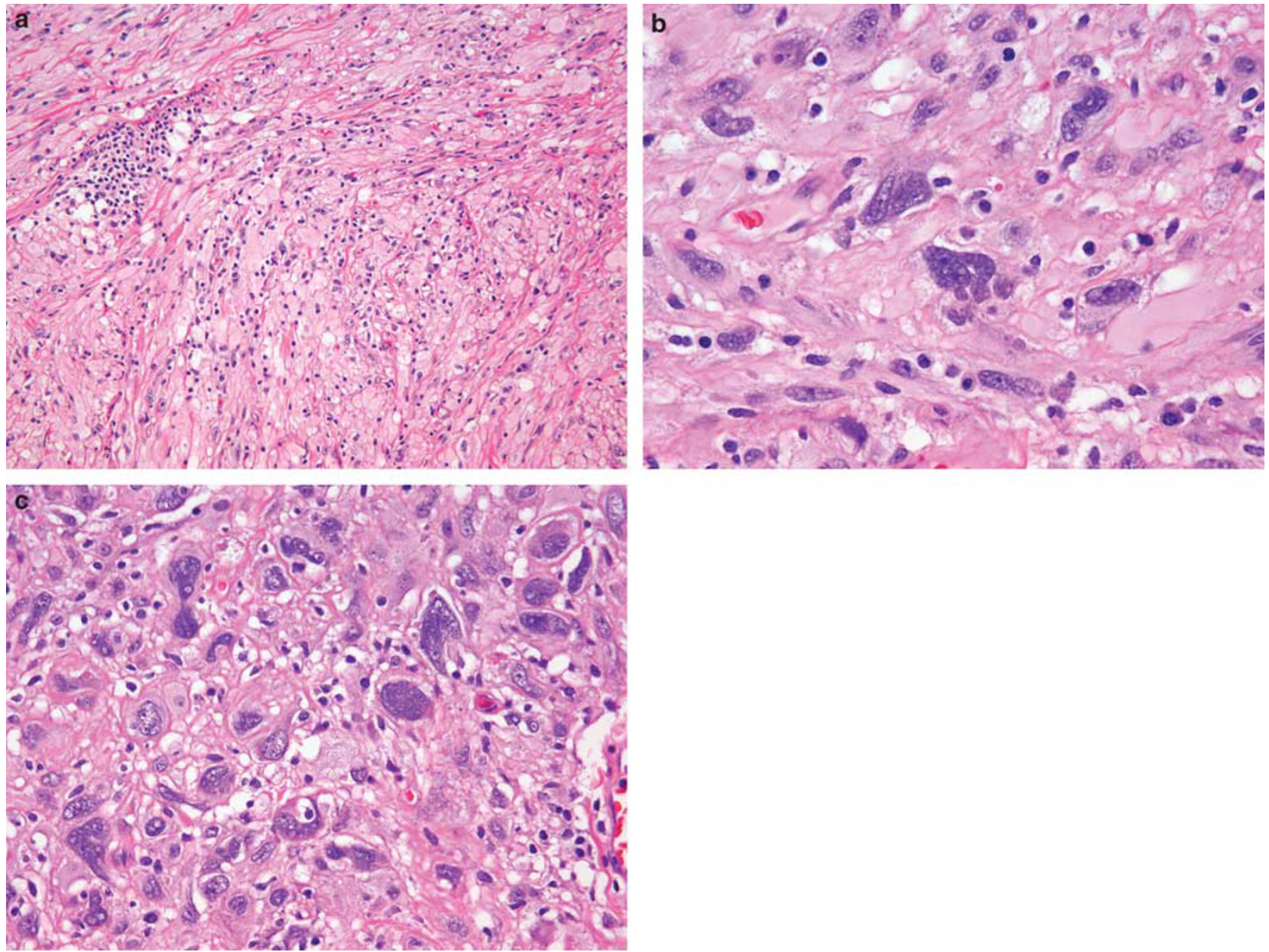

Figure 3 CD34-positive fibroblastic tumors were composed of spindled-to-epithelioid cells with abundant, eosinophilic cytoplasm, often having an unusual 'glassy' appearance (a). Higher-power view of 'glassy' eosinophilic cytoplasm (b). In some cases, the cytoplasm of the neoplastic cells showed a granular, rather than 'glassy' appearance (c).

tumor might also raise the question of a possible relationship to pleomorphic hyalinizing angiectatic tumor. ${ }^{10,11}$ As noted above, one case from the present series was seen in consultation by other soft-tissue experts, and was thought to most likely represent a variant of pleomorphic hyalinizing angiectatic tumor. However, the present lesion lacks the low-grade, hemosiderin-rich spindle cell proliferation typically seen at the periphery of pleomorphic-hyalinizing angiectatic tumor, which we have termed 'early' pleomorphic-hyalinizing angiectatic tumor ${ }^{11}$ and others have termed 'hemosiderotic fibrolipomatous tumor'. ${ }^{27-30}$ In addition, superficial CD34-positive fibroblastic tumor lacks the ectatic blood vessels and striking hemosiderin deposition that typify pleomorphic-hyalinizing angiectatic tumor and often shows cytokeratin expression.

Myxoinflammatory fibroblastic sarcoma (inflammatory myxohyaline tumor of distal extremities) also shares some morphological features with superficial CD34-positive fibroblastic tumor, including bizarre-appearing cells with prominent nucleoli, a generally low mitotic rate, a prominent chronic inflammatory cell infiltrate, and rarely cytokeratin expression. ${ }^{8,9,12}$ However, myxoinflammatory fibroblastic sarcoma typically involves acral locations, lacks cells with abundant granular cytoplasm, contains prominent myxoid and acellular hyaline zones, the former with pseudolipoblasts, lacks diffuse CD34 expression, and often shows rearrangements of the TGFBR3 and MGEA5 genes. ${ }^{12,31,32}$ In addition, the degree of atypia shown by superficial CD34-positive fibroblastic tumor exceeds that typically seen in myxoinflammatory fibroblastic sarcoma.

The CD34 and cytokeratin co-expression shown by superficial CD34-positive fibroblastic tumor also raise the possibility of some relationship to epithelioid sarcoma or an epithelioid endothelial cell tumor. The morphological features of the present lesion are obviously quite different from those of epithelioid sarcoma of both classical and proximal type. ${ }^{33,34}$ Furthermore, the lesions that we have described show retained expression of SMARCB1, unlike the great majority of epithelioid sarcomas. ${ }^{35}$ 

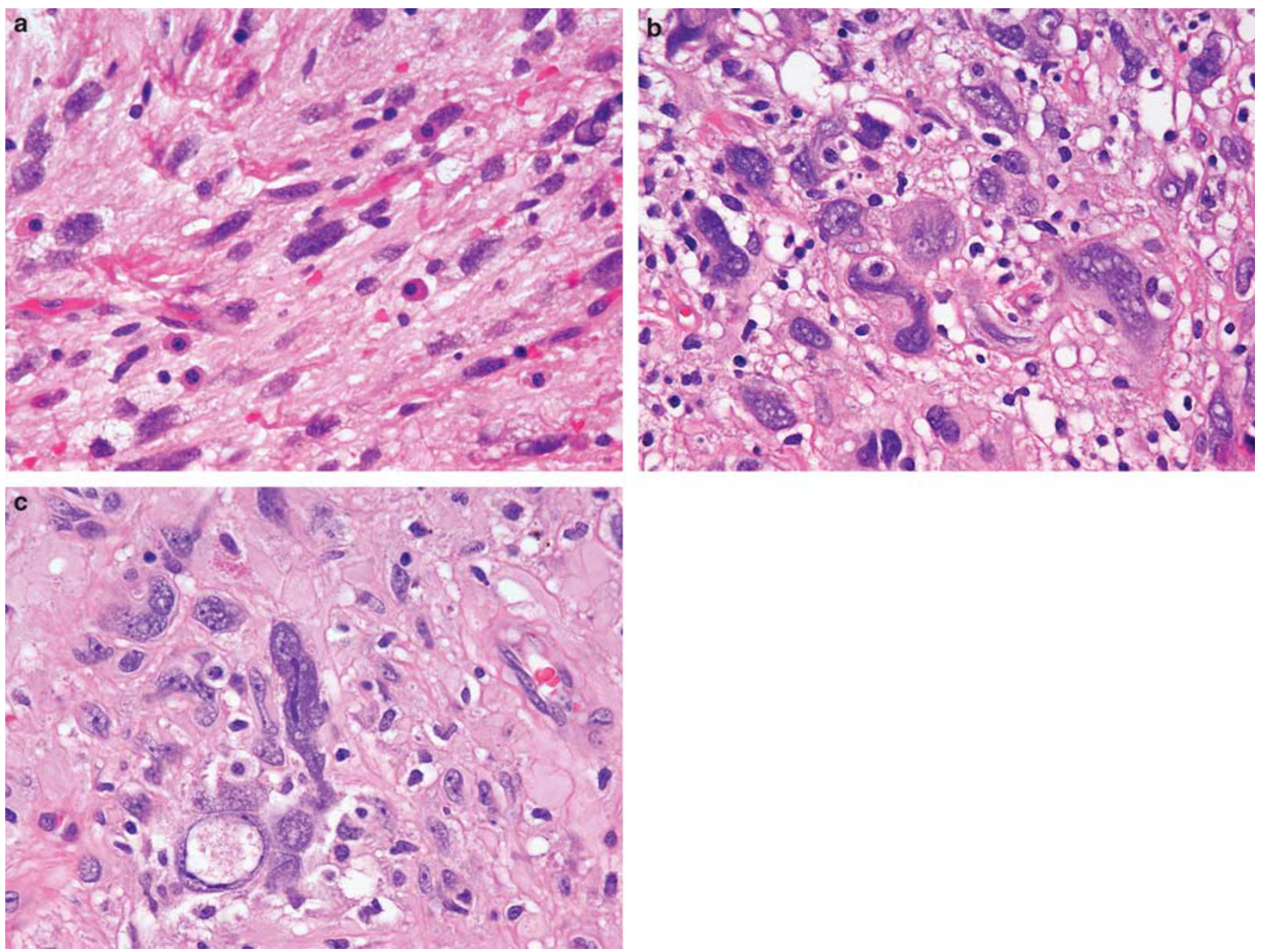

Figure 4 Although small areas with these tumors sometimes consisted of relatively monomorphic spindled cells (a), all tumors were notable for very striking nuclear pleomorphism, with enlarged, bizarre-appearing, hyperchromatic nuclei (b). Giant macronucleoli and intranuclear pseudoinclusions were also frequently present (c). Note also the mixed chronic inflammatory cell infiltrate present in all cases, including mast cells.
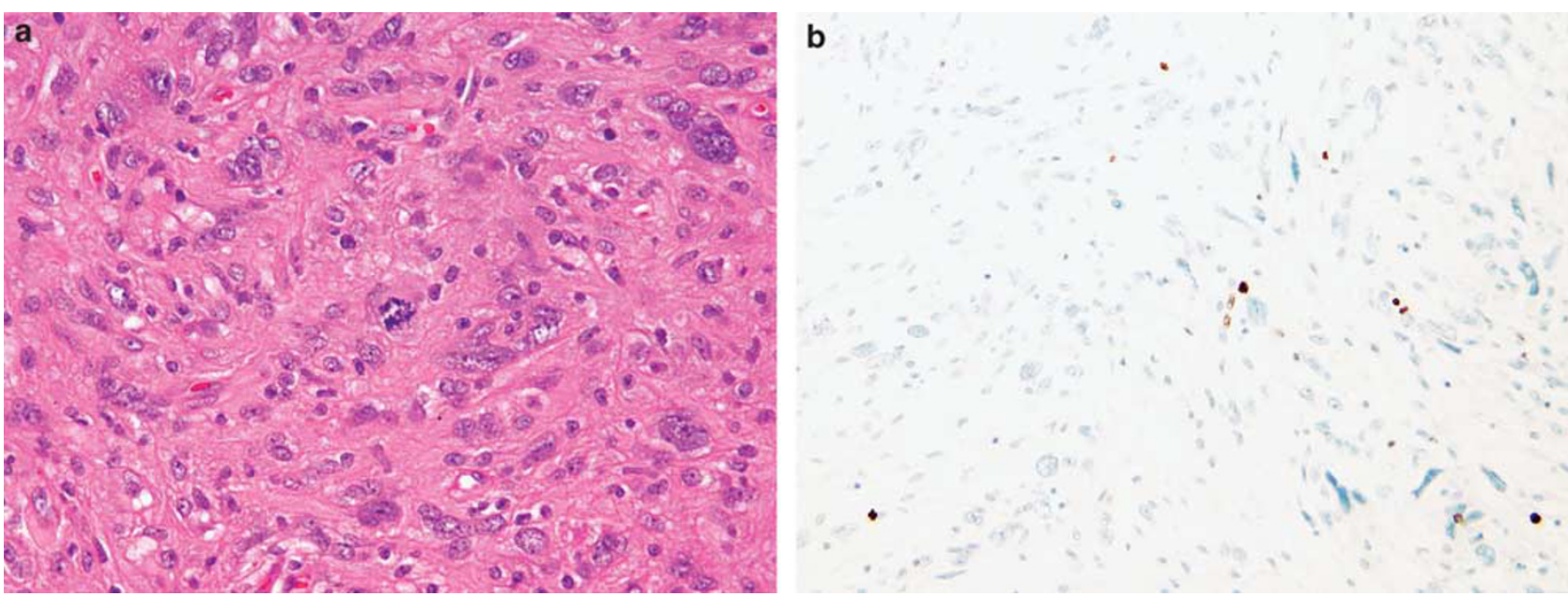

Figure 5 Despite their striking nuclear pleomorphism, CD34-postive fibroblastic tumors show an extremely low mitotic rate, invariably $<1 / 50$ high-powered fields (HPFs). One of the only mitotic figures identified is shown (a). Similarly, the Ki-67-labeling index was also extremely low (b). 

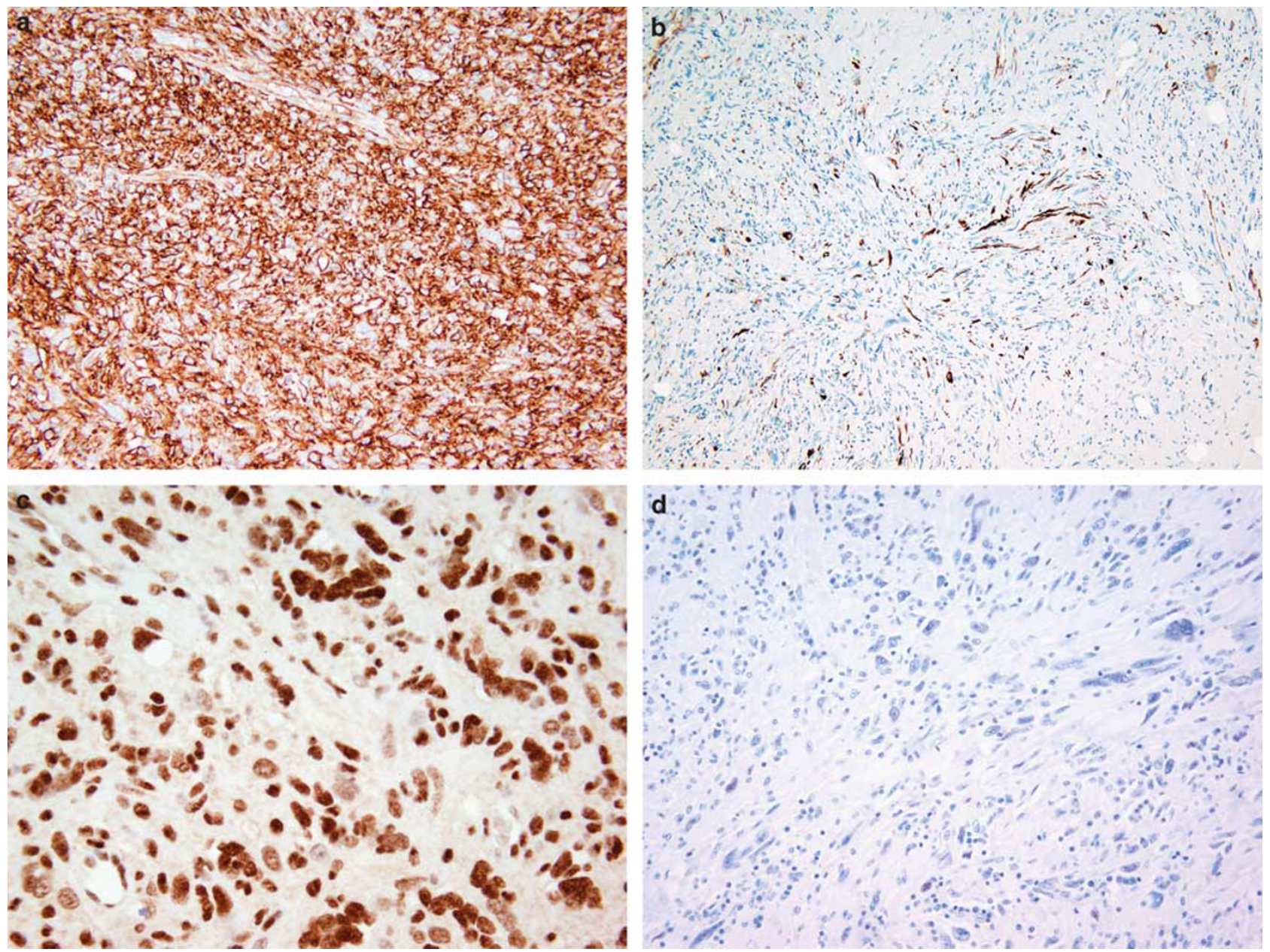

Figure 6 All tumors strongly expressed CD34 (a), and most of them were also positive for cytokeratins (b). In contrast, SMARCB1 expression was always retained (c) and p53 overexpression was absent.

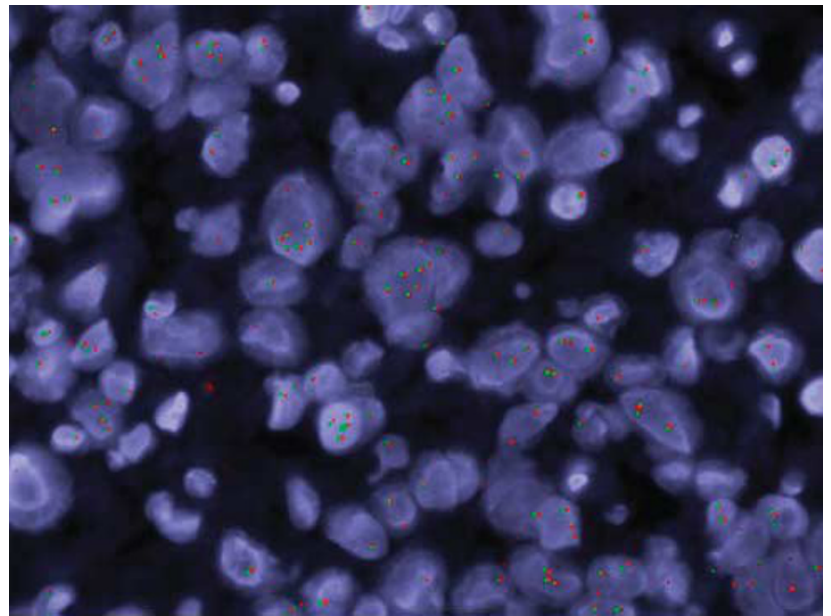

Figure 7 Negative fluorescence in-situ hybridization (FISH) for the myxoinflammatory fibroblastic sarcoma-associated MGEA5 gene. All tested cases were negative for MGEA5 and TGFBR3 rearrangement.

Similarly, the morphological features of superficial CD34-positive fibroblastic sarcoma are quite dissimilar from those of epithelioid angiosarcoma, ${ }^{36}$

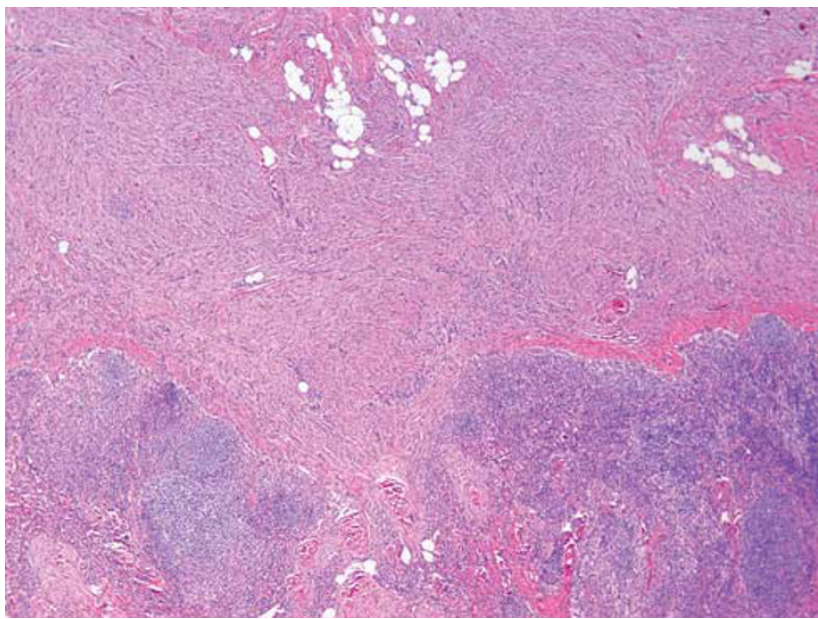

Figure 8 One case of CD34-positive fibroblastic tumor metastasized to a regional lymph node. Distant metastases were not seen.

epithelioid hemangioendothelioma, ${ }^{37}$ and epithelioid sarcoma-like hemangioendothelioma, ${ }^{38,39}$ and these tumors lack expression of the endothelial markers FLI-1 and ERG. ${ }^{40-42}$ 
The superficial location of these lesions might also raise the question of a possible relationship to dermatofibrosarcoma protuberans or cutaneous fibrous histiocytoma. Important points arguing against these possibilities include the subcutaneous (as opposed to dermal) location of these tumors, the lack of any history of a prior cutaneous tumor in the locations where these lesions arose, and the absence of any morphological features of dermatofibrosarcoma or fibrous histiocytoma at the periphery of the tumors. Fibrosarcomas arising in dermatofibrosarcoma protuberans typically show a herringbone pattern of growth, monomorphic cytology, brisk mitotic activity, and diminished CD34 expression, features very different than those of superficial CD34-positive fibroblastic tumor.

Finally, the abundant granular cytoplasm shown by these lesions might also suggest malignant granular cell tumor. Malignant granular cell tumors often show a component of pre-existing benignappearing granular cell tumor, consist of a relatively monomorphic spindle cell sarcoma, resembling conventional malignant peripheral nerve sheath tumor, and are $S 100$ protein positive ${ }^{43}$

In summary, we have reported the clinical, pathological, immunohistochemical, and molecular cytogenetic features of a novel mesenchymal tumor of the superficial soft tissues, which we have termed 'superficial CD34-positive fibroblastic tumor'. On the basis of available follow-up information, this tumor appears to behave as a mesenchymal tumor of intermediate malignancy (rarely metastasizing) to use current the World Health Organization nomenclature. ${ }^{44}$ Longer-term follow-up and accrual of additional cases will be required to more fully understand the natural history of this distinctive lesion and whether it, like other low-grade fibroblastic mesenchymal tumors, has a characteristic molecular signature. Careful morphological evaluation and appropriate ancillary studies should allow for the distinction of superficial CD34-positive fibroblastic tumors from potential morphological mimics, in particular undifferentiated pleomorphic sarcoma.

\section{Disclosure/conflict of interest}

The authors declare no conflict of interest.

\section{References}

1 Evans HL. Desmoplastic fibroblastoma. A report of seven cases. Am J Surg Pathol 1995;19:1077-1081.

2 Bahrami A, Folpe AL. Adult-type fibrosarcoma: A reevaluation of 163 putative cases diagnosed at a single institution over a 48-year period. Am J Surg Pathol 2010;34:1504-1513.

3 Evans HL. Low-grade fibromyxoid sarcoma. A report of two metastasizing neoplasms having a deceptively benign appearance. Am J Clin Pathol 1987;88:615-619.
4 Meis-Kindblom JM, Kindblom LG, Enzinger FM. Sclerosing epithelioid fibrosarcoma. A variant of fibrosarcoma simulating carcinoma. Am J Surg Pathol 1995;19:979-993.

5 Angervall L, Kindblom LG, Merck C. Myxofibrosarcoma. A study of 30 cases. Acta Pathol Microbiol Scand A 1977;85A:127-140.

6 Weiss SW, Enzinger FM. Myxoid variant of malignant fibrous histiocytoma. Cancer 1977;39:1672-1685.

7 Connelly JH, Evans HL. Dermatofibrosarcoma protuberans. A clinicopathologic review with emphasis on fibrosarcomatous areas. Am J SurgPathol 1992;16:921-925.

8 Meis-Kindblom JM, Kindblom LG. Acral myxoinflammatory fibroblastic sarcoma: a low-grade tumor of the hands and feet. Am J of Surg Pathol 1998;22:911-924.

9 Montgomery EA, Devaney KO, Giordano TJ, et al. Inflammatory myxohyaline tumor of distal extremities with virocyte or Reed-Sternberg-like cells: a distinctive lesion with features simulating inflammatory conditions, Hodgkin's disease, and various sarcomas. Mod Pathol 1998;11:384-391.

10 Smith ME, Fisher C, Weiss SW. Pleomorphic hyalinizing angiectatic tumor of soft parts. A low-grade neoplasm resembling neurilemoma. Am J Surg Pathol 1996;20:21-29.

11 Folpe AL, Weiss SW. Pleomorphic hyalinizing angiectatic tumor: analysis of 41 cases supporting evolution from a distinctive precursor lesion. Am J Surg Pathol 2004;28:1417-1425.

12 Antonescu CR, Zhang L, Nielsen GP, et al. Consistent $t(1 ; 10)$ with rearrangements of TGFBR3 and MGEA5 in both myxoinflammatory fibroblastic sarcoma and hemosiderotic fibrolipomatous tumor. Genes Chrom Cancer 2011;50:757-764.

13 Kindblom LG, Merck C, Svendsen P. Myxofibrosarcoma: a pathologico-anatomical, microangiographic and angiographic correlative study of eight cases. Br J Radiol 1977;50:876-887.

14 Merck C, Angervall L, Kindblom LG, et al. Myxofibrosarcoma. A malignant soft tissue tumor of fibroblastic-histiocytic origin. A clinicopathologic and prognostic study of 110 cases using multivariate analysis. Acta Pathol Microbiol Immunol Scand Suppl 1983;282:1-40.

15 Mentzel T, Calonje E, Wadden C, et al. Myxofibrosarcoma. Clinicopathologic analysis of 75 cases with emphasis on the low-grade variant. Am J Surg Pathol 1996;20:391-405.

16 Wada T, Hasegawa T, Nagoya S, et al. Myxofibrosarcoma with an infiltrative growth pattern: a case report. Jpn J Clin Oncol 2000;30:458-462.

17 Beer TW, Drury P, Heenan PJ. Atypical fibroxanthoma: a histological and immunohistochemical review of 171 cases. Am J Dermatopathol 2010;32:533-540.

18 Orosz Z, Kelemen J, Szentirmay Z. Granular cell variant of atypical fibroxanthoma. Pathol Oncol Res 1996;2:244-247.

19 Rios-Martin JJ, Delgado MD, Moreno-Ramirez D, et al. Granular cell atypical fibroxanthoma: report of two cases. Am J Dermatopathol 2007;29:84-87.

20 Rudisaile SN, Hurt MA, Santa Cruz DJ. Granular cell atypical fibroxanthoma. J Cutan Pathol 2005;32: 314-317.

21 Wang J, Coltrera MD, Gown AM. Abnormalities of p53 and p110RB tumor suppressor gene expression in human soft tissue tumors: correlations with cell proliferation and tumor grade. Mod Pathol 1995;8:837-842. 
22 Perot G, Chibon F, Montero A, et al. Constant p53 pathway inactivation in a large series of soft tissue sarcomas with complex genetics. Am J Pathol 2010; 177:2080-2090.

23 Leach FS, Tokino T, Meltzer P, et al. p53 Mutation and MDM2 amplification in human soft tissue sarcomas. Cancer Res 1993;53:2231-2234.

24 Yang $\mathrm{P}$, Hirose $\mathrm{T}$, Hasegawa $\mathrm{T}$, et al. Prognostic implication of the p53 protein and Ki-67 antigen immunohistochemistry in malignant fibrous histiocytoma. Cancer 1995;76:618-625.

25 Szadowska A, Olborski B, Harezga-Bal B, et al. Immunohistochemical status of p53, mdm2 and Ki-67 in malignant fibrous histiocytoma. Pol J Pathol 1998; 49:15-21.

26 Oda Y, Takahira T, Kawaguchi K, et al. Altered expression of cell cycle regulators in myxofibrosarcoma, with special emphasis on their prognostic implications. Hum Pathol 2003;34:1035-1042.

27 Marshall-Taylor C, Fanburg-Smith JC. Hemosiderotic fibrohistiocytic lipomatous lesion: ten cases of a previously undescribed fatty lesion of the foot/ankle. Mod Pathol 2000;13:1192-1199.

28 Browne T-J, Fletcher CD. Hemosiderotic fibrohistiocytic lipomatous tumor (so-called): validation of a distinct entity. Lab Invest 2004;84:11A.

29 Luzar B, Gasljevic G, Juricic V, et al. Hemosiderotic fibrohistiocytic lipomatous lesion: early pleomorphic hyalinizing angiectatic tumor? Pathol Int 2006;56: 283-286.

30 Moretti VM, de la Cruz M, Brooks JS, et al. Early pleomorphic hyalinizing angiectatic tumor: precursor or distinct lesion? Orthopedics 2010;33:516.

31 Elco CP, Marino-Enriquez A, Abraham JA, et al. Hybrid myxoinflammatory fibroblastic sarcoma/hemosiderotic fibrolipomatous tumor: report of a case providing further evidence for a pathogenetic link. Am J Surg Pathol 2010;34:1723-1727.

32 Hallor KH, Sciot R, Staaf J, et al. Two genetic pathways, $\mathrm{t}(1 ; 10)$ and amplification of 3p11-12, in myxoinflammatory fibroblastic sarcoma, haemosiderotic fibrolipomatous tumour, and morphologically similar lesions. J Pathol 2009;217:716-727.
33 Enzinger FM. Epithelioid sarcoma: a sarcoma simulating a granuloma or a carcinoma. Cancer 1970;26:1029-1041.

34 Guillou L, Wadden C, Coindre JM, et al. "Proximaltype" epithelioid sarcoma, a distinctive aggressive neoplasm showing rhabdoid features. Clinicopathologic, immunohistochemical, and ultrastructural study of a series. Am J Surg Pathol 1997;21:130-146.

35 Hollmann TJ, Hornick JL. INI1-deficient tumors: diagnostic features and molecular genetics. Am J Surg Pathol 2011;35:e47-e63.

36 Fletcher CD, Beham A, Bekir S, et al. Epithelioid angiosarcoma of deep soft tissue: a distinctive tumor readily mistaken for an epithelial neoplasm. Am J Surg Pathol 1991;15:915-924.

37 Weiss SW, Enzinger FM. Epithelioid hemangioendothelioma: a vascular tumor often mistaken for a carcinoma. Cancer 1982;50:970-981.

38 Billings SD, Folpe AL, Weiss SW. Epithelioid sarcomalike hemangioendothelioma. Am J Surg Pathol 2003; 27:48-57.

39 Hornick JL, Fletcher CD. Pseudomyogenic hemangioendothelioma: a distinctive, often multicentric tumor with indolent behavior. Am J Surg Pathol 2011; 35:190-201.

40 Folpe AL, Chand EM, Goldblum JR, et al. Expression of Fli-1, a nuclear transcription factor, distinguishes vascular neoplasms from potential mimics. Am J Surg Pathol 2001;25:1061-1066.

41 McKay KM, Doyle LA, Lazar AJ, et al. Expression of ERG, an Ets family transcription factor, distinguishes cutaneous angiosarcoma from histological mimics. Histopathol 2012;61:30.

42 Miettinen M, Wang ZF, Paetau A, et al. ERG transcription factor as an immunohistochemical marker for vascular endothelial tumors and prostatic carcinoma. Am J Surg Pathol 2011;35:432-441.

43 Fanburg-Smith JC, Meis-Kindblom JM, Fante R, et al. Malignant granular cell tumor of soft tissue: diagnostic criteria and clinicopathologic correlation. Am J Surg Pathol 1998;22:779-794.

44 Fletcher CDM, Bridge JA, Hogendoorn PCW. WHO Classification of Tumours of Soft Tissue and Bone, 4th edn. IARC Press: Lyon, France, 2013, pp 10-11. 